\title{
'PENGARUH KEPUASAN KERJA, LOYALITAS KARYAWAN DAN KEMAMPUAN KARYAWAN TERHADAP KEINGINAN KARYAWAN UNTUK PINDAH KERJA PADA KOPERASI 212 MART DI KOTA TANGERANG.'
}

\author{
M. Tony Nawawi ${ }^{1}$, Sanny Ekawati ${ }^{2}$ \\ ${ }^{1}$ Fakultas Ekonomi \& Bisnis Universitas Tarumanagara, Jakarta \\ Email : tonyn@fe.untar.ac.id \\ ${ }^{2}$ Fakultas Ekonomi \& Bisnis Universitas Tarumanagara, Jakarta \\ Email : $\underline{\text { sanny@fe.untar.ac.id }}$
}

\begin{abstract}
The company has realized that its human resources are an important asset for the company and also as partners. Because human resources contribute to the company by carrying out their roles and duties in company activities, the company should understand very well what the rights and obligations of employees are, so that the company management pays attention to the various needs needed by employees, so that the company can maintain good relations with its employees. With a good relationship with employees, it can maintain employee loyalty to the company, and ultimately there will be employee job satisfaction. This study aims to determine the effect of job satisfaction, employee loyalty, and employee ability on the desire of employees to change jobs at the 212 Mart Cooperative in Tangerang City. Researchers in taking samples using non-probability sampling. The number of samples used in this study were 100 respondents who currently work as employees at the 212 Mart Cooperative. The data obtained by distributing questionnaires, then processed with the help of Smart PLS analysis. From the test results it can be concluded that job satisfaction does not have a positive but significant effect on the desire of employees to change jobs, and employee loyalty has a positive but not significant effect on the desire of employees to change jobs, while the ability of employees has a positive and significant influence on the desire of employees to move. Work at 212 Mart Cooperative in Tangerang City.
\end{abstract}

Keywords: job satisfaction; loyalty; ability; desire to change jobs

\begin{abstract}
ABSTRAK
Perusahaan telah menyadari bahwa sumber daya manusia yang dimilikinya adalah menjadi asset penting bagi perusahaan dan juga sebagai mitra kerja. Karena sumber daya manusia memberikan konstribusi kepada perusahaan dengan menjalankan peran dan tugasnya dalam kegiatan perusahaan, maka perusahaan sebaiknya memahami betul apa yang menjadi hak dan kewajiban karyawan, sehingga pihak manajemen perusahaan memperhatikan berbagai kebutuhan yang diperlukan karyawan, agar perusahaan dapat menjaga hubungan baik dengan karyawannya. Dengan adanya hubungan yang baik dengan karyawan dapat menjaga loyalitas karyawan terhadap perusahaan, dan akhirnya akan ada kepuasan kerja karyawan, sehingga. Penelitian ini bertujuan untuk mengetahui Pengaruh Kepuasan Kerja, Loyalitas karyawan, dan Kemampuan karyawan terhadap Keinginan karyawan Pindah Kerja Pada Koperasi 212 Mart di Kota Tangerang. Peneliti dalam pengambilan sampel menggunakan non-probability sampling. Jumlah sampel yang digunakan dalam penelitian ini sebanyak 100 orang responden yang saat ini bekerja sebagai karyawan di Koperasi 212 Mart. Data yang didapatkan dengan penyebaran angket, kemudian diolah dengan bantuan analisis Smart PLS . Dari hasil pengujian dapat disimpulkan bahwa Kepuasan Kerja tidak memiliki pengaruh yang positif tapi signifikan Terhadap Keinginan karyawan Pindah Kerja, dan Loyalitas karyawan memiliki pengaruh yang positif tapi tidak signifikan Terhadap Keinginan karyawan Pindah Kerja, sedangkan Kemampuan karyawan memiliki pengaruh yang positif dan signifikan Terhadap Keinginan karyawan Pindah Kerja Pada Koperasi 212 Mart di Kota Tangerang.
\end{abstract}

Kata kunci: kepuasan kerja;loyalitas;kemampuan;keinginan pindah kerja

\section{PENDAHULUAN}

\section{Latar Belakang}

Setiap perusahaan telah menyadari bahwa Karyawan merupakan asset yang penting, karena karyawan (sdm) dapat memberikan konstribusi kepada perusahaan dengan menjalankan peran 
dan tugasnya pada perusahaan. Oleh karena itu, perusahaan sebaiknya memahami betul apa yang menjadi hak dan kewajiban karyawan serta juga memperhatikan berbagai kebutuhan karyawan agar perusahaan dapat menjaga hubungan baik antara perusahaan dengan karyawan. Hubungan yang baik dengan karyawan dapat mennciptakan rasa loyalitas karyawan terhadap perusahaan. Disamping itu, karyawan juga dalam pekerjaannya sebaiknya mendapatkan reward atas kinerja yang telah diberikan setimpal dengan apa yang telah dikerjakannya sehingga akan berdampak terhadap tingkat kepuasan kerja karyawan. Jika tingkat kepuasan kerja karyawan tinggi maka akan meningkatkan sikap loyalitas karyawan tersebut terhadap perusahaan, sedangkan jika tingkat kepuasan karyawan rendah maka akan mengakibatkan adanya keinginan karyawan untuk berhenti bekerja. 'Apabila seorang karyawan meninggalkan perusahaan, maka perusahaan harus melakukan pergantian karyawan. Jika di perusahaan sering terjadi pergantian karyawan maka akan mengganggu kelancaran proses produksi. Permasalahan tersebut biasanya dialami oleh perusahaan yang memiliki tingkat perputaran (turn over) yang tinggi'. Untuk itu penulis melakukan penelitian untuk mengetahui hal - hal apa saja yang dapat mempengaruhi kepuasan kerja dan loyalitas bagi seorang karyawan dan apakah hal tersebut berpengaruh terhadap keinginan karyawan tersebut untuk pindah. Studi ini akan berfokus untuk meneliti apakah ada pengaruh antara kepuasan kerja dan loyalitas karyawan terhadap keinginan karyawan tersebut untuk pindah. Pada penelitian ini yang menjadi permasalahannya adalah Apakah kepuasan kerja berpengaruh terhadap keinginan karyawan untuk pindah kerja di Koperasi 212 Mart Kota Tangerang ?,Apakah loyalitas karyawan berpengaruh terhadap keinginan karyawan untuk pindah kerja di Koperasi 212 Mart Kota Tangerang ?,Apakah kemampuan karyawan berpengaruh terhadap keinginan karyawan untuk pindah kerja di Koperasi 212 Mart Kota Tangerang? 'Adapun tujuan dari penelitian ini adalah :Untuk mengetahui pengaruh kepuasan kerja terhadap keinginan karyawan untuk pindah kerja di Koperasi 212 Mart Kota Tangerang.,Untuk mengetahui pengaruh loyalitas terhadap keinginan karyawan untuk pindah kerja di Koperasi 212 Mart Kota Tangerang;Untuk mengetahui pengaruh kemampuan karyawan terhadap keinginan karyawan untuk pindah kerja di Koperasi 212 Mart Kota Tangerang'.

\section{METODE PENELITIAN}

\section{a. Desain Penelitian}

'Penelitian ini menggunakan desain penelitian kausal. Desain penelitian kausal digunakan untuk menguji pengaruh variabel perlakuan terhadap variabel dependen. Variabel perlakuan itu sendiri harus direncanakan berdasarkan teori tertentu'. 'Istilah "pengaruh" seharusnya hanya digunakan pada penelitian yang menggunakan desain penelitian kausal'. (-----------, (2010). Metode Penelitian Kuantitatif, Kualitatif, 2010) mengemukakan bahwa metode kausal merupakan hubungan yang memiliki sifat sebab akibat yang meliputi variabel independen dan variabel dependen. 'Dengan menggunakan metode kausal, diharapkan akan mendapatkan informasi yang tepat dan akurat mengenai pengaruh kepuasan kerja $\left(\mathrm{X}_{1}\right)$, loyalitas $\left(\mathrm{X}_{2}\right)$ dan kemampuan karyawan $\left(\mathrm{X}_{3}\right)$ terhadap keinginan karyawan untuk pindah kerja $(\mathrm{Y})$ '.

\section{b. Populasi dan Teknik Pemilihan Sampel}

\section{Populasi}

Menurut (Aritonang R., 2017) populasi merupakan keseluruhan unsur yang menjadi subyek penelitian. (Sugiyono, 2013) "menjelaskan bahwa populasi adalah wilayah generalisasi yang terdiri atas obyek atau subyek yang memiliki kualitas dan karakteristik tertentu yang ditetapkan oleh peneliti untuk dipelajari dan kemudian diambil kesimpulannya".

Dalam penelitian ini, yang menjadi populasi adalah karyawan pada Koperasi 212 Mart sejumlah 145 orang. 


\section{Teknik Pemilihan Sampel}

Menurut (Aritonang R., 2017) "sampel adalah bagian dari polulasi. Sedangkan menurut (Sugiyono, 2003) sampel merupakan bagian dari jumlah dan karakteristik yang dimiliki oleh populasi tersebut".

Teknik pengambilan sampel yang digunakan adalah purposive random sampling yaitu 'teknik pengambilan sampel secara tak acak berdasarkan tujuan sebanyak 100 orang. 'Subjek yang diteliti dalam penelitian ini adalah karyawan bagian kantor yang telah memiliki pengalaman dan pengetahuan yang memadai dalam bagian operasi di Kota tangerang'.

\section{c. Operasional Variabel}

'Menurut (Aritonang R., 2017) pengertian dari operasional variable adalah' "penelitian yang berisi semua kegiatan yang akan dilakukan untuk memperoleh data empiris kuntitatif mengenai variasi karakteristik variabel tersebut; merupakan spesifikasi apa yang diukur dan bagaimana cara mengukurnya".

\section{1. 'Kepuasan Kerja'}

'Definisi mengenai kepuasan kerja yang dikemukakan oleh (Mathis, Robert L., 2010) adalah "job Satisfaction is a positive emotional state resulting from evaluating one"s job experience",yang artinya suatu keadaan emosional positif yang merupakan hasil dari evaluasi pengalaman kerja seseorang'.

'Untuk penelitian ini, indicator yang digunakan untuk mengukur kepuasan kerja karyawan diambil dari jurnal yang dibuat oleh (Faisal Mahdi, Ahmad, 2012)"

2. 'Loyalitas karyawan'

Menurut (Marchelle Soegandhi, Vannecia, 2013), "loyalitas dari seorang karyawan berarti seorang karyawan bersedia bekerja di organisasi tempat dia bekerja dan karyawan tersebut bersedia untuk melakukan yang terbaik demi kesuksesan organisasi dan dia berpikir bahwa bekerja di organisasi tempat dia bekerja adalah pilihan yang terbaik baginya'.

"Untuk penelitian ini, indikator yang digunakan untuk mengukur loyalitas karyawan diambil dari (Dessler, 2011)"

3. 'Kemampuan karyawan'

Menurut (Hasibuan, SP, 2015) "kemampuan kerja adalah suatu hasil kerja yang dicapai seseorang dalam melaksanakan tugas-tugas yang dibebankan kepadanya yang didasarkan atas kecakapan, pengalaman, dan kesungguhan serta waktu".

'Dalam penelitian ini kemampuan kerja akan diukur dengan indikator yang dikemukakan oleh (Robbins, 2007)'.

4. 'Keinginan karyawan ingin pindah kerja'

'Keinginan karyawan untuk pindah kerja (Turnover Intention) merupakan keinginan individu untuk meninggalkan perusahaan dan mencari pekerjaan lain'. Menurut (Mathis, Robert L., 2010), "perputaran karyawan adalah "process in which employess leave the organization and have to be replaced" yang artinya proses dimana karyawan meninggalkan organisasi dan perlu untuk digantikan".

'Untuk penelitian ini, indikator yang digunakan untuk mengukur keinginan karyawan untuk pindah kerja diambil dari jurnal yang dibuat oleh (Faisal Mahdi, Ahmad, 2012)'

\section{d. Teknik Uji Validitas dan Reliabilitas.}

"Untuk menunjukan bahwa instrumen layak dipakai, maka instrumen harus memenuhi dua kriteria yaitu valid dan reliabel. 'Instrumen yang valid berarti alat ukur yang digunakan untuk mendapatkan data sesuai dengan apa yang seharusnya diukur, sementara instrumen yang reliabel adalah instrumen yang bila dipakai untuk mengukur objek yang sama dapat menghasilkan data yang sama" (----------, (2010). Metode Penelitian Kuantitatif, Kualitatif, 2010)" 
Seminar Nasional Hasil Penelitian dan Pengabdian Kepada Masyarakat 2021

Pengembangan Ekonomi Bangsa Melalui Inovasi Digital Hasil Penelitian dan

Pengabdian Kepada Masyarakat

Jakarta, 21 Oktober 2021

1. Uji Validitas

Menurut (Aritonang R., 2017) "validitas merupakan suatu instrumen berkaitan dengan kemampuan instrumen tersebut untuk mengukur atau mengungkapkan karakteristik dari variabel yang akan diukur'.

"Penelitian ini menggunakan bantuan perangkat lunak PLS 3.2, Menurut Cronbach (1990) yang dikutip pada (Aritonang R., 2017) jika hasil dari yang diuji $\geq 0,20$ maka dinyatakan valid.

Apabila hasilnya kurang dari 0,20 maka dinyatakan tidak valid".

2. Uji Reliabilitas

Menurut (Sugiyono, 2013) "mengemukakan instrumen yang reliabel adalah instrumen yang apabila digunakan beberapa kali untuk mengukur objek atau subjek yang sama, akan menghasilkan data yang sama. Analisis reliabilitas dilakukan terhadap butir-butir yang masih valid, sedangkan butir-butir yang dinyatakan gugur harus diperbaiki”.

"Uji reliabilitas digunakan untuk mengetahui apakah instrumen memiliki indeks kepercayaan yang baik jika diujikan berulang. Sebuah instrument pengukuran dikatakan reliabel jika hasilnya konsisten dan akurat, Pengukuran reliabilitas akan diukur melalui uji Cronbach Alpha dengan bantuan perangkat lunak PLS 32.0 dan akan dinilai reliabel jika nilai dari Cronbach Alpha $\geq 0,70$. Dimana apabila hasil koefisien reliabilitas minimal 0,7 maka dinyatakan reliable".

\section{HASIL DAN PEMBAHASAN}

Metode Analisis Data

Berikut disajikan hasil uji model struktural (Inner Model Analysisi) dari data yang telah diolah dengan Smart PLS sbb, :

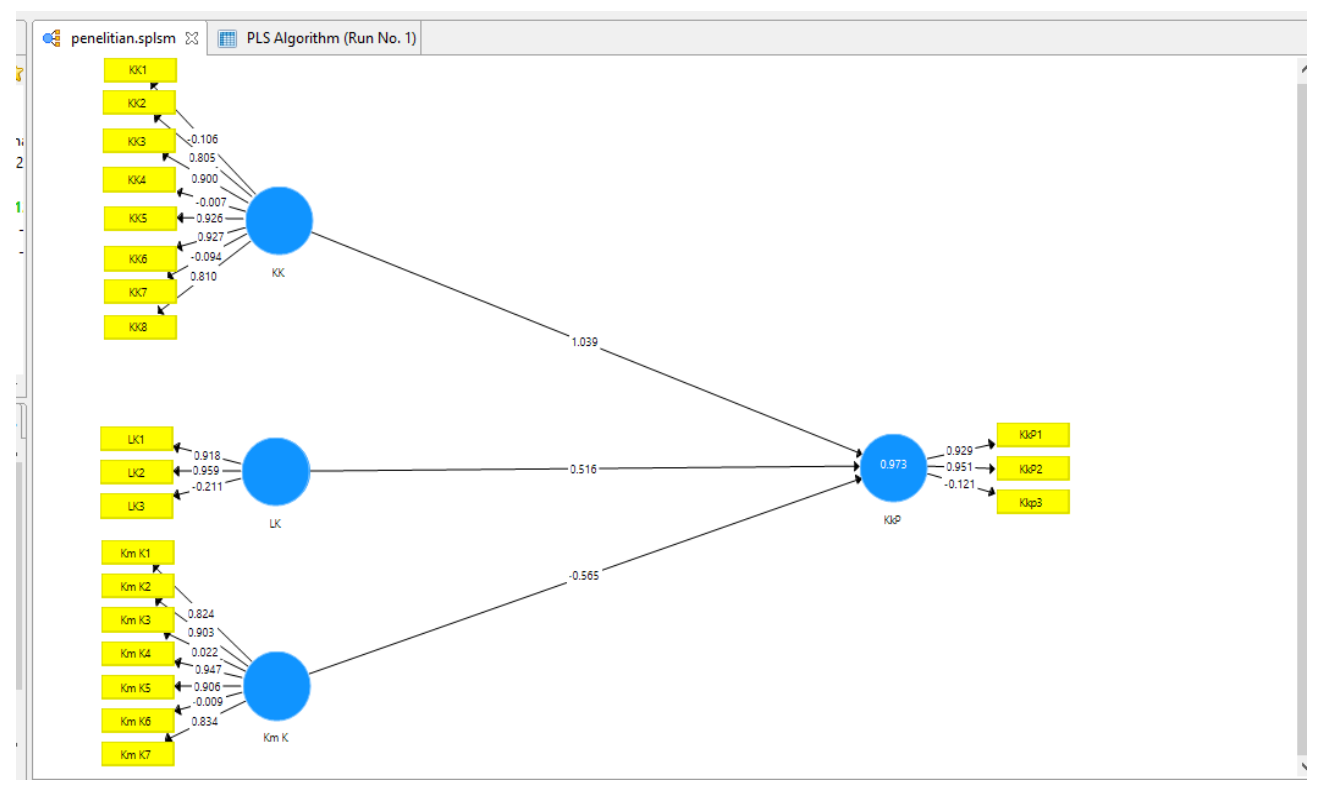

Gambar 1. Model Penelitian

Sumber : Diolah Smart PLS, 2021

\section{Uji Koefisien Determinasi atau $R$-square}

"Uji $R$-square dilakukan untuk menentukan seberapa besar variabel dependen mampu dijelaskan oleh variabel indpenedennya'. Berdasarkan (Hair, 2011) jika nilai $R$-square 0,67 maka dikatakan kuat, 0,33 moderat, 0,19 lemah“. 
Tabel 1. Hasil Uji Koefisien Determinasi

\begin{tabular}{|c|c|c|}
\hline Variabel & & $R$-square \\
\hline $\begin{array}{l}\text { Keinginan } \\
\text { Karyawan }\end{array}$ & Pindah Kerja & 0.972 \\
\hline
\end{tabular}

Sumber : Data Primer, 2021

Berdasarkan table 1 diatas, "menunjukan adanya kesimpulan bahwa model structural pada penelitian ini tergolong "kuat". Pada variabel Keinginan Pindah kerja Karyawan nilai dari $R$ square sebesar 0.972 atau dalam persentase sebesar 97,2\% yang artinya variabel endogen dapat dijelaskan melalui variasi variabel eksogen yang ada dalam penelitian ini sebesar 97,2\%, kemudian 13,8\% lainnya dijelaskan oleh faktor lain".

\section{Uji $Q$-square}

'Dalam $Q$-square jika nilai $\mathrm{Q}>0$ maka dapat dikatakan variabel eksogen memiliki relevansi prediktif terhadap variabel endogen. Menurut (Hair, J. F., Risher, J. J., Sarstedt, M., \& Ringle, 2019) jika nilai $Q$-square 0 atau dikatakan memiliki relevansi prediktif yang kecil, nilai 0,26 memiliki nilai relevansi yang sedang, dan nilai lebih dari 0,50 memiliki relevansi prediktif yang besar.'

Table 2. Hasil Uji $Q$-square

\begin{tabular}{llll}
\hline Variabel & & & $Q$-square \\
\hline Keinginan & Pindah & Kinerja & 0.971 \\
Karyawan & & & \\
\hline
\end{tabular}

Sumber : Data Primer, 2021

"Hasil penelitian menggunakan SmartPLS untuk menguji $Q$-square menunjukan hasil sebesar 0.971 atau sebesar $97,1 \%$ seperti pada table 2 . Berdasarkan hasil tersebut dapat disimpulkan nilai $Q$-square pada penelitian ini termaksud pada golongan prediksi "relevansi yang besar".

\section{Path coefficient}

'Path coefficient diuji untuk mengukur pengaruh antar variabel-variabel yang telah ditetapkan sesuai dengan hipotesis yang diuji. Menurut (Hair, J. F., Risher, J. J., Sarstedt, M., \& Ringle, 2019) nilai path coefficient yang semakin dekat dengan 0 menunjukan hubungan yang lemah dan jika nilai kurang dari 0 menunjukan adanya hubungan yang tidak signifikan'.

Tabel 3. Hasil Uji Path coefficient

\begin{tabular}{lll}
\hline \multicolumn{1}{c}{ Variabel } & Path coefficient \\
\hline $\mathrm{KK}=>\mathrm{KpK}$ & -0.063 & \\
\hline $\mathrm{LK}=>\mathrm{KpK}$ & 0.714 \\
\hline $\mathrm{KmK}=>\mathrm{KpK}$ & 0.334 & \\
\hline
\end{tabular}

Sumber : Data Primer, 2021 
"Berdasarkan hasil uji path coefficient pada Tabel 3 diatas, untuk Keinginan karyawan Pindah Kerja secara langsung nilai dari kepuasan kerja sebesar -0.063, loyalitas Karyawan pengaruh sebesar 0.714, 'kemampuan karyawan mempengaruhi keinginan pindah kerja karyawan sebesar 0.334', yang artinya masing-masing variabel berpengaruh positip secara kuat terhadap Keinginan pindah kerja karyawan karena nilai yang diperoleh lebih besar dari 0 , sedangkan variable kepuasan kerja memiliki pengaruh negatip terhadap keinginan karyawan pindah kerja".

\section{Uji Hipotesis dan Significance test}

'Pada significance test, pengujian menggunakan nilai t-statistik dan $\mathrm{p}$ value. Yang dimana nilai tstatistik lebih besar dari 1,96 dan p-value lebih kecil dari $0,05^{`}$.

Tabel 4. Hasil Uji hipotesis

\begin{tabular}{llll}
\hline Variabel & t-statistik & P-value & Hasil \\
\hline $\mathrm{KK}=>\mathrm{KpK}$ & 3.192 & 0.001 & Ditolak \\
\hline $\mathrm{LK}=>\mathrm{KpK}$ & 2.439 & 0.008 & Ditolak \\
\hline $\mathrm{KmK}=>\mathrm{KpK}$ & 1.447 & 0.074 & Tidak Ditolak \\
\hline
\end{tabular}

Sumber : Data Primer, 2021

Berdasarkan tabel 4 diatas maka dapat dijelaskan sebagai berikut:

Hipotesis 1: Hasilnya Ditolak, karena nilai t-hitung $(3,192)>$ nilai t tabel $(1,96)$, artinya bahwa kepuasan kerja tidak berpengaruh positip secara signifikan terhadap keinginan karyawan pindah kerja'.

Hipotesis 2: "Hasilnya Ditolak, karena nilai t-hitung $(2,439)>$ nilai t tabel $(1,96)$, artinya bahwa Loyalitas karyawan tidak berpengaruh positif secara signifikan terhadap keinginan karyawan pindah kerja“".

Sedangkan untuk Hipotesis 3: "Hasilnya Tidak Ditolak (Diterima), karena nilai t-hitung $(1,447)<$ nilai t-tabel $(1,96)$, artinya bahwa kemampuan karyawan memiliki pengaruh langsung secara tidak signifikan terhadap keinginan karyawan pindah kerja“.

\section{Pembahasan}

1. Kepuasan Kerja dan Keinginan karyawan Pindah

Berdasarkan penelitian yang sudah dilakukan untuk menguji Hipotesis $\mathrm{H}_{1}$, variabel Kepuasan Kerja tidak memiliki pengaruh yang positif (negatif) dan signifikan terhadap Keinginan karyawan Pindah' .

Hal ini sesuai dengan penelitian yang dilakukan oleh (Pawirosumarto, 2018) "dimana Kepuasan Kerja memiliki pengaruh dengan Keinginan karyawan Pindah, yang dimana salah satu hal yang terpenting menurut hasil penelitian tersebut adalah kedisiplinan dan ketegasan seorang Atasan yang sangat dibutuhkan agar pegawai mampu menjaga Kerjasama".

2. Loyalitas karyawan dan Keinginan karyawan Pindah

Dalam penelitian ini loyalitas karyawan menemukan hasil pengaruh yang positif dan tidak signifikan terhadap keinginan pindah karyawan sehingga dapat dikatakan bahwa loyalitas karyawan tidak memiliki peran langsung terhadap keinginan pindah karyawan. Kesimpulan ini bertolak belakang dengan hasil penelitian oleh (Sihaloho, R. D., 2019) namun beberapa studi empiris lain menemukan hasil yang sama layaknya pada penelitian ini seperti juga yang 
dilakukan oleh (Pawirosumarto, 2018) melakukan penelitian tentang loyalitas karyawan terhadap keinginan pindah karyawan dan menemukan hasil yang positif dan signifikan“.

3. Kemampuan Karyawan, dan Keinginan karyawan Pindah

"Dalam penelitian ini diperoleh hasil ada pengaruh yang positif dan signifikan antara Kemampuan Karyawan dan Keinginan karyawan Pindah. Hal ini sejalan dengan hasil penelitian yang dilakukan oleh (Ihsani \& Wijayanto, 2020)".

Dalam (Ihsani \& Wijayanto, 2020) bahwa "Kemampuan Karyawan mengarahkan karyawan untuk mencapai tujuan bersama organisasi, sehingga dapat menurunkan keinginan pindah kerja. Hal ini menunjukkan bahwa karyawan memiliki kemampuan, perhatian, dan fokus yang tinggi dalam melaksanakan pekerjaannya".

\section{KESIMPULAN DAN SARAN}

Adapun Kesimpulan dai hasil penelitian ini adalah sebagai berikut:

1. Hasil dari penelitian ini menunjukan bahwa Kepuasan kerja tidak memiliki pengaruh positip secara signifikan terhadap keinginan pindah kerja karyawan.

2. Dalam penelitian ini loyalitas karyawan memiliki pengaruh yang positif dan tidak signifikan terhadap keinginan pindah kerja karyawan.

3. Dalam penelitian ini ditemukan bahwa kemamapuan karyawan memiliki pengaruh yang positif dan signifikan terhadap Keinginan pindah kerja karyawan.

Sedangkan saran yang dapat direkomendasikan sebagai berikut untuk Koperasi 212 Mart di Kota Tangerang. maupun peneliti selanjutnya :

a. Untuk Koperasi 212 Mart di Kota Tangerang Koperasi 212 Mart di Kota Tangerang, diharapkan agar lebih memotivasi karyawan, meningkatkan integrasi, dan meningkatkan upah karyawan agar dapat menurunkan tingkat keinginan pindah kerja karyawan.

b. Kemudian untuk penelitian selanjutnya, diharapkan untuk menggunakan metode-metode lain dalam pendekatannya, tidak hanya menggunakan penyebaran kuisioner secara daring, namun juga dengan wawancara.

\section{Ucapan Terima Kasih (Acknowledgement)}

Pada kesempatan ini kami mengucapkan banyak terima kasih kepada Ketua Lembaga Penelitian dan Pengabdian Kepada masyarakat Universitas Tarumanagara ( LPPM UNTAR) beserta Staf yang telah mendanai penelitian ini, dan juga Terima kasih kepada Koperasi 212 Mart kota Tangerang yg telah menjadi tempat penelitian ini. Semoga Bermanfaat.

\section{REFERENSI}

, (2010). Metode Penelitian Kuantitatif, Kualitatif, dan R. bandung: C. A. (2010). Metode Penelitian Kuantitatif, Kualitatif, dan $R \& D$. cv alfabeta.

Aritonang R., L. R. (2017). Riset pemasaran. teori dan praktik. Ghalia Indonesia.

Dessler, G. (2011). Human resource management, human resource management (10th Edition) ((10th). Paramita Rahayu Translation,.

Faisal Mahdi, Ahmad, D. (2012). The Relationship Between Job Satisfaction and Turnover Intention. American Journal of Applied Sciences, 9(9), 1518-1526.

Hair, J. F., Risher, J. J., Sarstedt, M., \& Ringle, C. M. (2019). When to use and how to report the results of PLS-SEM. European Business Review, 31(1), 2-24.

Hair, et al. (2011). Multivariate Data Analysis (New Intern). Pearson Education.

Hasibuan, SP, M. (2015). Manajemen Sumber Daya Manusia (MSDM) (edisi Revi). Bumi aksara. 
Ihsani, N., \& Wijayanto, A. (2020). THE EFFECT OF ORGANIZATIONAL CULTURE, MOTIVATION, AND JOB SATISFACTION ON EMPLOYEE PERFORMANCE. Dinasti International Journal of Digital Business Management, 1(4).

Marchelle Soegandhi, Vannecia, D. (2013). Pengaruh Kepuasan Kerja dan Loyalitas Kerja Terhadap Organizational Citizenship Behavior Pada Karyawan PT. Surya Timur Sakti Jatim. Jurnal Program Manajemen Bisnis, 1(1), 1-12.

Mathis, Robert L., \& J. H. J. (2010). Human Resources Management. Thomson Learning.

Pawirosumarto, S. (2018). The Influence of Work Stress, Working Cost, Compensation and Work Discipline on Employee' Productivity. International Journal of Economics and Business Administration, VI(4), 65-72.

Robbins, S. P. (2007). Perilaku Organisasi. Index.

Sihaloho, R. D., \& S. (2019). Pengaruh Lingkungan Kerja Terhadap Kinerja Karyawan pada PT Super Setia Sagita Medan. Jurnal Ilmiah Socio Secretum, 9(2), 273-281. https://jurnal.darmaagung.ac.id

Sugiyono. (2003). Metode Penelitian Kuantitatif Kualitatif dan R\&D. Alfabeta.

Sugiyono. (2013). Metode Penelitian Pendidikan Pendekatan Kuantitatif, Kualitatif, dan R\&D. Alfabeta. 